\title{
Aqüífero Guarani: gestão compartilhada e soberania
}

\author{
WAGNER COSTA RIBEIRO
}

\section{Á} GUA DOCE e de qualidade é vital à existência humana. Além disso, ela deve estar próxima aos usuários. O aumento do uso dos recursos hídricos em escala mundial levará a um uso ainda mais intenso das reservas de água subterrânea. Isso já ocorre em muitos lugares onde ela está disponível. Entretanto, as águas subterrâneas se distribuem irregularmente no interior da superfície terrestre e não respeitam limites fronteiriços de países. Esse é mais um elemento a ser considerado na gestão dos recursos hídricos em escala internacional.

A gestão compartilhada das águas internacionais, as que se distribuem por mais de um país como um corpo d'água superficial ou como reserva subterrânea, deve ser um dos temas mais debatidos nesse início de século XXI. As discussões estão mais avançadas quando se trata dos recursos superficiais. As 263 principais bacias internacionais têm sido analisadas por diversos especialistas. ${ }^{1}$ Um dos casos mais conhecidos resultou na Convenção de Helsinque, que desde 1992 regulamentou o uso compartilhado da água envolvendo países europeus. Porém, são ainda escassas as análises tratando da gestão compartilhada da água subterrânea.

Países como Brasil, Argentina, Uruguai e Paraguai, que integram o Mercado Comum do Sul (Mercosul), partilham um imenso reservatório hídrico interior e não devem enfrentar dificuldades para abastecimento populacional ou para outros usos da água. Entretanto, devem regulamentar o acesso a ela para que não ocorra sua contaminação nem o esgotamento dos recursos hídricos.

Este trabalho analisa a oferta de água subterrânea do aqüífero Guarani. Além disso, procura apontar a situação institucional do Mercosul em relação à gestão compartilhada dos recursos hídricos.

Inicialmente se fará uma exposição do quadro físico do aqüífero. Depois, o Mercosul e seus organismos de gestão ambiental serão discutidos na perspectiva de avaliar a pertinência em deslocar para esse bloco de países a coordenação da gestão do Sistema Aqüífero Guarani (SAG).

\section{O Sistema Aqüífero Guarani}

O Sistema Aqüífero Guarani está distribuído por uma área de cerca de $1.196 .500 \mathrm{~km}^{2}$. Situado na porção Centro-Leste do continente sul-americano, distribui-se pelo território de quatro países do Cone Sul, todos membros do Mercosul: Argentina, com $225.500 \mathrm{~km}^{2}$; Paraguai, com uma área de 71.700 $\mathrm{km}^{2}$; Uruguai, onde ocupa cerca de $58.500 \mathrm{~km}^{2}$; e Brasil, país onde chega a algo em torno de $840.800 \mathrm{~km}^{2}$ (Figura 1). 


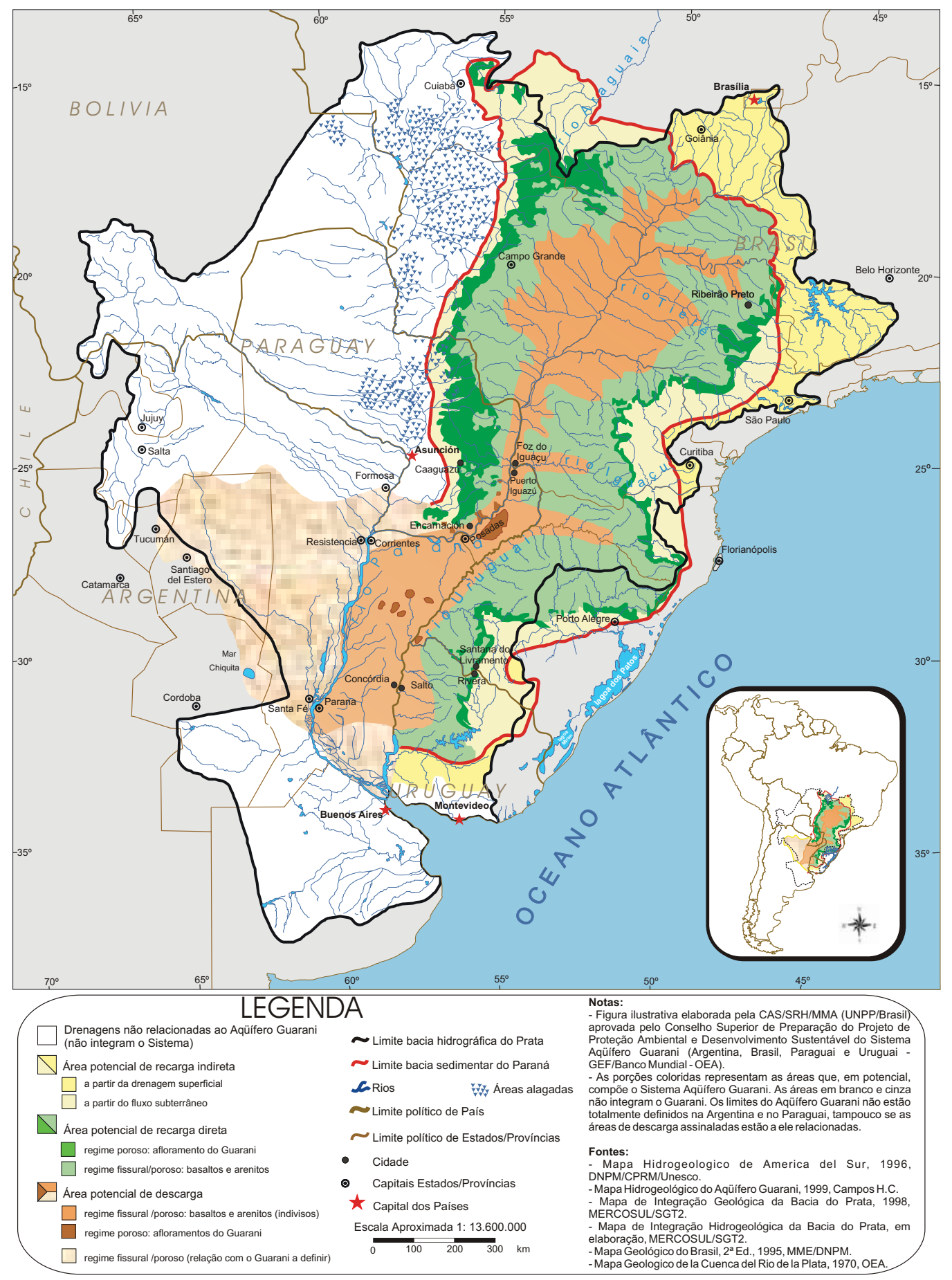

Fonte: www.sg-guarani.org, acessado em dezembro de 2005.

Figura 1 - Mapa esquemático do Sistema Aqüífero Guarani.

Além de conter a maior parte das reservas subterrâneas, o Brasil também conta com muitas áreas de recarga, o que lhe confere uma posição estratégica. Nesse país, o aqüífero se dispersa ao longo de oito Estados da Federação: 
Mato Grosso do Sul, com uma área de $213.200 \mathrm{~km}^{2}$; Rio Grande do Sul, com $157.600 \mathrm{~km}^{2}$; São Paulo, com $155.800 \mathrm{~km}^{2}$; Paraná, com $131.300 \mathrm{~km}^{2}$; Goiás, com $55.000 \mathrm{~km}^{2}$; Minas Gerais, com $52.300 \mathrm{~km}^{2}$; Santa Catarina, com 49.200; e Mato Grosso, com $26.400 \mathrm{~km}^{2}$.

O Sistema Aqüífero Guarani resulta de diversas formações geológicas situadas no Triássico e no Jurássico. Tiveram origem no Triássico as Formações Pirambóia e Rosário do Sul, no Brasil, e a Formação Buena Vista, no Uruguai. Remontam ao Jurássico as Formações Botucatu, no Brasil, Misiones, no Paraguai, e Tacuarembó, que ocorre na Argentina e no Uruguai (Rocha, 1997).

Os arenitos do Triássico têm origem flúvio-lacustre e alcançam uma porosidade média de 16\%, em razão dos elevados índices de argila, o que dificulta o fluxo de água no interior da rocha (Araújo et al., 1995). Os arenitos do Jurássico têm origem eólica e uma porosidade média de 17\%. Neles ocorrem os melhores reservatórios de água do sistema (ibidem).

As rochas arenosas saturadas de água estão entremeadas por rochas basálticas da Formação Serra Geral que resultaram de intrusões desse material. A espessura desse pacote de rocha arenosa oscila entre 200 e $800 \mathrm{~m}$. Porém, além de aflorar em diversos pontos do território dos países citados, ela chega a atingir $1.800 \mathrm{~m}$ de profundidade. Por isso, existe uma variação importante na temperatura da água, que em alguns pontos chega a $65^{\circ} \mathrm{C}$ e, em outros, aflora a temperatura ambiente oscilando próximo a $20^{\circ} \mathrm{C}$. O mapa da Figura 2 indica os pontos conhecidos de afloramento do aqüífero.

A condição de aqüífero confinado é estabelecida pelas rochas vulcânicas da Formação Serra Geral e pelas rochas sedimentares triássicas e jurássicas. Por isso, é freqüente o artesianismo que se verifica em cerca de $70 \%$ da área de ocorrência (Borghetti et al., 2004).

Uma das controvérsias científicas ainda sem esclarecimento diz respeito à distribuição do aqüífero. Por estar confinado entre rochas vulcânicas, sem porosidade, admite-se que o aqüífero não está como um corpo poroso contínuo no qual ocorre água (ibidem). Ele está entrecortado por rochas intrusivas que o fracionam. Essa irregularidade leva à definição do Sistema Aqüífero Guarani, uma série de corpos d'água subterrânea que podem estar isolados ou não. Outro aspecto pouco conhecido é a comunicação entre esses corpos. Haveria comunicação entre eles? Se sim, eles devem ser pensados como um conjunto que dispõe de água transferindo-a internamente. Mas e se não ocorrerem vasos comunicantes? Nesse caso, há quem advogue que a gestão compartilhada não se aplica. Daí a necessidade em aprofundar estudos que analisem a hidrogeologia do aqüífero para que se possam esclarecer esses aspectos, que implicam diretamente a gestão dos recursos hídricos do Sistema Aqüífero Guarani.

Estima-se que a quantidade de água do aqǘfero seja em torno de 46.000 $\mathrm{km}^{3}$ (Borghetti et al., 2004). Em estudo muito anterior, o geólogo brasileiro Aldo Rebouças (1976) estimou as reservas em 48.000 km³. Porém, a reposição 


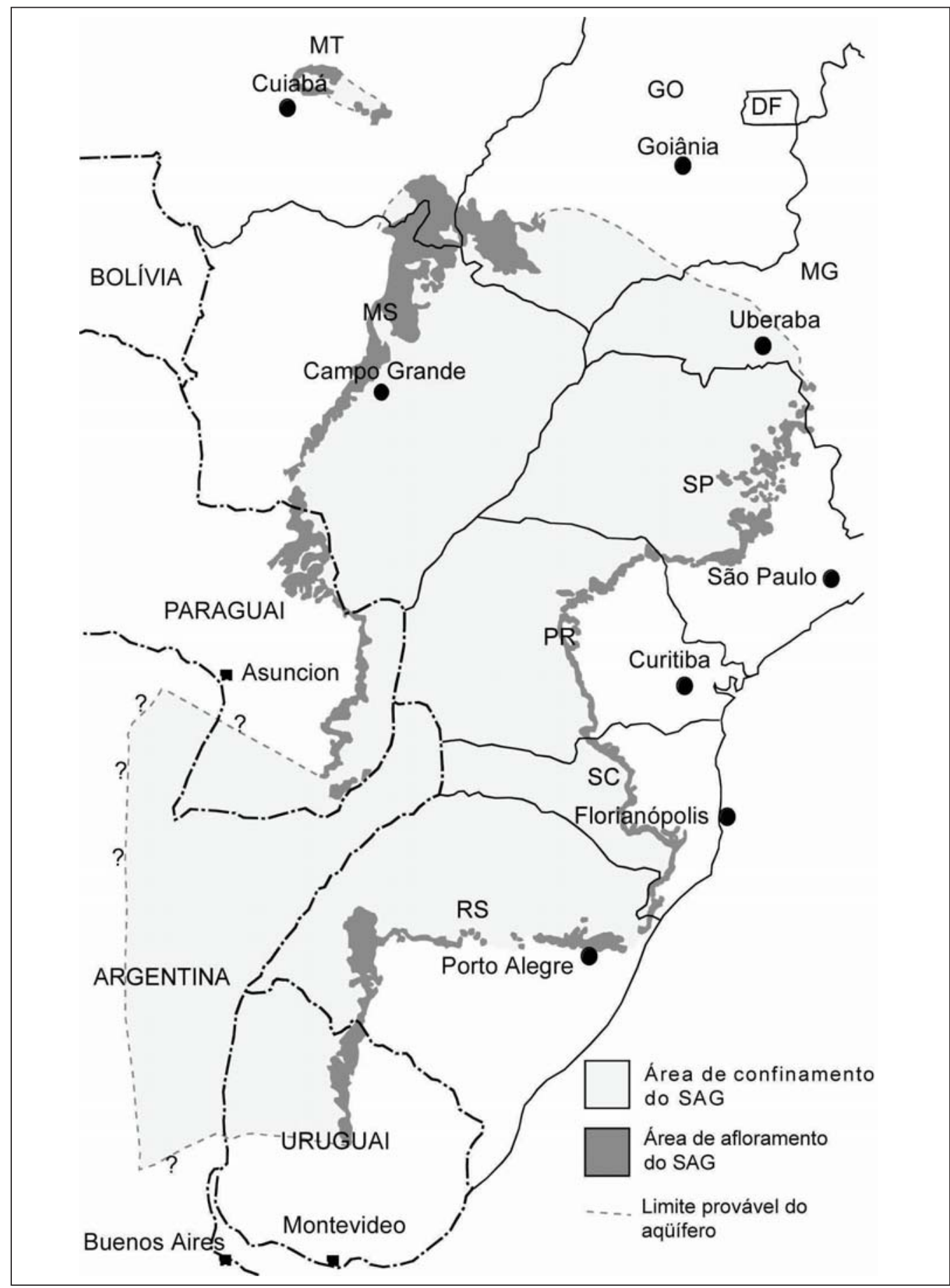

Fonte: OEA (2001).

Escala Aproximada 1: 10.000.000

Figura 2 - Áreas de afloramento do Sistema Aqüífero Guarani.

de água, oriunda de chuvas nas áreas de recarga, é estimada em aproximadamente $166 \mathrm{~km}^{3} /$ ano ou $5 \mathrm{mil} \mathrm{m} 3 / \mathrm{s}$. Considerando-se perdas, chegou-se a um volume de $40 \mathrm{~km}^{3} /$ ano de água utilizável, segundo divulgou o Departamento 
de Águas e Energia do Estado de São Paulo. ${ }^{2}$ Esse volume de água é mais que suficiente para abastecer os cerca de 15 milhões de habitantes que vivem sobre a superfície do aqüífero (Araújo et al., 1995). ${ }^{3}$

Embora as reservas de água subterrânea já estejam em uso em diversas localidades, não existe ainda uma estrutura organizada para a gestão dos recursos hídricos do Sistema Aqüífero Guarani. Apesar da controvérsia sobre o isolamento de partes do sistema, especula-se que o uso desequilibrado possa afetar a dinâmica da oferta de água. Daí ser fundamental conhecer o arranjo institucional usado como parâmetro de gestão dos recursos hídricos no Mercosul, pois os países em que essa água está disponível integram esse bloco de países. A expectativa é avaliar se os instrumentos que tal bloco oferece propiciam um uso compartilhado dos recursos subterrâneos do Sistema Aqüífero Guarani.

\section{O Mercosul}

A intenção de articular os países do Cone Sul em um bloco de países surgiu em meados da década de 1980, quando o Brasil e a Argentina assinaram acordos para a redução gradual de tarifas alfandegárias. A inversão de interesses de países até então oposicionistas e que se afirmavam mutuamente como inimigos é um dos principais aspectos desse momento vivenciado na América do Sul. A aproximação de dois rivais parecia distender tensões acumuladas ao longo da história. Esperava-se que uma articulação entre esses países resultasse em uma ordem baseada no entendimento e na paz entre os membros do continente sul-americano.

Esse quadro favorável permitiu a criação do Mercosul. Em 1991, em reunião realizada em Assunção, Paraguai, chegou-se ao Tratado de Assunção, que criou o Mercosul integrando Argentina, Brasil, Paraguai e Uruguai. ${ }^{4}$ Esse documento é um acordo-quadro, portanto, amplo. Ele expressava o desejo da integração, mas não a regulamentou. Mesmo assim, o Tratado de Assunção já expressava preocupações ambientais, como consta em seu preâmbulo:

Considerando que a ampliação das atuais dimensões de seus mercados nacionais, através da integração constitui condição fundamental para acelerar seus processos de desenvolvimento econômico com justiça social;

Entendendo que esse objetivo deve ser alcançado mediante o aproveitamento mais eficaz dos recursos disponíveis a preservação do meio ambiente, melhoramento das interconexões físicas a coordenação de políticas macroeconômica da complementação dos diferentes setores da economia, com base nos princípios de gradualidade, flexibilidade e equilíbrio. (Mercosul, 1991, grifo do autor)

A integração de mercados nacionais, objetivo central da criação do Mercosul, deveria ponderar a preservação ambiental e melhorar as interconexões físicas. A temática ambiental está claramente referenciada do mesmo modo que se pode interpretar que a integração tratava também das bases físicas, fossem elas naturais ou construídas.

Em 1994, na reunião de Ouro Preto, no Brasil, definiu-se a estrutura institucional do Mercosul. Apesar disso, o bloco ainda carece de uma efetiva 
implementação. Grande parte das determinações de Ouro Preto ainda está a cumprir.

O Protocolo de Ouro Preto definiu a seguinte estrutura institucional: o Conselho do Mercado Comum (CMC); o Grupo Mercado Comum (GMC); a Comissão de Comércio do Mercosul (CCM); a Comissão Parlamentar Conjunta (CPC); o Foro Consultivo Econômico-Social (FCES); e a Secretaria Administrativa do Mercosul (SAM). Além dessa estrutura, funciona também a Reunião de Ministros, ocasião em que estes se reúnem de acordo com suas pastas e procuram assessorar e subsidiar as deliberações do CMC.

O Conselho do Mercado Comum é o principal foro decisório e é composto pelos ministros das Relações Exteriores e pelos ministros da Economia, ou seus equivalentes, dos Estados-parte. A presidência do CMC cabe a cada um dos países membros e se alterna de seis em seis meses, por ordem alfabética.

O Grupo Mercado Comum é o braço executivo do bloco. Segundo o artigo 11 do Protocolo de Ouro Preto, "será integrado por quatro membros titulares e quatro membros alternos por país, designados pelos respectivos Governos, dentre os quais devem constar necessariamente representantes dos Ministérios das Relações Exteriores, dos Ministérios da Economia (ou equivalentes) e dos Bancos Centrais. O Grupo Mercado Comum será coordenado pelos Ministérios das Relações Exteriores" (Mercosul, 1994).

A Comissão de Comércio do Mercosul se reúne ao menos uma vez ao mês e é composta por indicação dos respectivos Ministérios de Relações Exteriores. Já a Comissão Parlamentar Conjunta congrega os Parlamentos dos países-membros, que devem indicar os representantes, cuja função é apresentar recomendações ao CMC.

O Foro Consultivo Econômico-Social é o órgão de representação dos setores econômicos e sociais e será integrado por igual número de representantes de cada Estado-parte. Ele foi criado para atender a uma demanda de organizações sindicais e populares que procuravam estar mais presentes e influenciar as decisões do CMC. Entretanto, não consegue atuar como previsto. Por fim, à Secretaria Administrativa cabe emitir documentos em nome do Mercosul, bem como arquivar a documentação. Ela é dirigida por um diretor eleito, com mandato de dois anos, no GMC.

Em 1998, na reunião de Ushuaia, na Argentina, foi definido mais um protocolo de destaque. Ele reforçou um compromisso que havia sido acordado pelos membros criadores: manter a democracia em seus Estados. Tal exigência era compreensível em razão das ditaduras que os quatro membros enfrentaram, cada qual ao seu tempo, desde meados da década de 1960 até meados da década de 1980.

Mesmo com o reconhecimento de que o diálogo democrático era fundamental, foi preciso estabelecer um regime de resolução de eventuais problemas envolvendo as partes. Esse processo teve início em 1991, em reunião ocorrida 
em Brasília. Na ocasião, definiu-se o Protocolo de Brasília de Resolução de Controvérsias. A partir de então, o bloco passou a contar com um sistema de sanções entre as partes em caso de descumprimento de termos acordados por consenso, como estabelecia o Tratado de Assunção.

O Protocolo de Brasília definiu três etapas para a resolução de controvérsias: a negociação direta entre as partes - que não pode exceder a 15 dias; a conciliação, que deve ser obtida em até 30 dias por meio do Grupo Mercado Comum; e a arbitragem.

O Protocolo de Olivos, de 2002, aprofundou os termos do Protocolo de Brasília, revogando-o. Além disso, detalhou os procedimentos para a arbitragem. Cabe destacar que os laudos arbitrais devem ser aplicados no prazo fixado a critério do júri, e "são obrigatórios para os Estados partes na controvérsia a partir de sua notificação e terão, em relação a eles, força de coisa julgada" (Mercosul, 2002).

\section{A dimensão ambiental no Mercosul}

Dispostos sobre a bacia da Prata, uma área natural de escala considerável, era de esperar que os países do Mercosul tivessem uma maior articulação voltada à gestão dos recursos naturais, em especial dos recursos hídricos. Porém, não é o que se verifica. Como nos demais itens, a institucionalização do Mercosul ainda é incipiente, carece de maiores investimentos e vontade política para implementação.

Apesar disso, encontram-se documentos e deliberações que justificam uma inquietação voltada às questões ambientais. Elas são expressão do Subgrupo de Trabalho Meio Ambiente - número 6 (denominado SGT 6) que está vinculado ao Grupo Mercado Comum. Pode-se dizer que o Mercosul configura um subsistema da ordem ambiental internacional (Ribeiro, 2001).

Foi no âmbito do SGT 6 que foi elaborado e aprovado o Acordo Quadro sobre Meio Ambiente do Mercosul, em 22 de junho de 2001. Além dele, o foro de ministros também criou a Reunião de Ministros de Meio Ambiente do Mercosul, em 12 de dezembro de 2003. São essas as instâncias que tratam dos temas ambientais no Mercosul.

Enquanto a segunda procura ser um foro de influência política de representantes do poder executivo de cada parte nas discussões ambientais que funciona como uma espécie de consultor às decisões do Mercosul relacionadas ao meio ambiente, a outra reafirma compromissos da Conferência das Nações Unidas sobre o Meio Ambiente, realizada no Rio de Janeiro em 1992, em especial o do "desenvolvimento sustentável preconizado na Agenda 21" (Mercosul, 2001). Nela também se reafirma a cooperação entre as partes como instrumento central para a sustentabilidade entre as ações dos membros do bloco regional.

É no artigo $3^{\circ}$ que estão os princípios que orientam as partes, a saber:

a) promoção da proteção do meio ambiente e aproveitamento mais eficaz dos recursos disponíveis mediante a coordenação de políticas setoriais, com base nos princípios de gradualidade, flexibilidade e equilíbrio; 
b) incorporação da componente ambiental nas políticas setoriais e inclusão das considerações ambientais na tomada de decisões que se adotem no âmbito do Mercosul para fortalecimento da integração;

c) promoção do desenvolvimento sustentável por meio do apoio recíproco entre os setores ambientais e econômicos, evitando a adoção de medidas que restrinjam ou distorçam de maneira arbitrária ou injustificável a livre circulação de bens e serviços no âmbito do Mercosul;

d) tratamento prioritário e integral às causas e fontes dos problemas ambientais;

e) promoção da efetiva participação da sociedade civil no tratamento das questões ambientais; e

f) fomento à internalização dos custos ambientais por meio do uso de instrumentos econômicos e regulatórios de gestão. (Mercosul, 2001)

Entre esses princípios, destacam-se a incorporação dos temas ambientais na tomada de decisões, a promoção do desenvolvimento sustentável, que é definido nos moldes sugeridos na Declaração do Rio de Janeiro, de 1992, qual seja, manter o desenvolvimento econômico e conservar o ambiente para as gerações futuras, a participação da sociedade civil e a internalização dos custos ambientais. Esses aspectos conferem ao Acordo sobre Meio Ambiente do Mercosul um caráter progressista. Em geral, temas como participação popular e consideração de custos ambientais são relegados a segundo plano nos foros multilaterais. Mesmo em reuniões da Organização das Nações Unidas, por exemplo, a presença de organizações da sociedade civil é facultada como membros de delegações ou como observadores sem direito a voto. Já a internalização dos custos ambientais é foco de longas discussões em foros multilaterais e, em geral, é associada a princípios como o do poluidor-pagador.

Por se tratar de um acordo-quadro, ele deve ser complementado por regulamentação específica. Além disso, ele sugere, no artigo $6^{\circ}$, que, contando com a participação da sociedade civil, a legislação nacional sobre meio ambiente seja harmonizada às diretrizes gerais do Acordo.

A seguir, apresentam-se as quatro áreas, e respectivas subáreas, de atuação do Acordo de Meio Ambiente do Mercosul que devem ser regulamentadas por protocolos específicos. São elas:

1. Gestão sustentável dos recursos naturais

1.a. fauna e flora silvestres;

1.b. florestas;

l.c. áreas protegidas;

1.d. diversidade biológica;

l.e. biossegurança;

l.f. recursos hídricos;

l.g. recursos ictícolas e aqüícolas;

l.h. conservação do solo.

2. Qualidade de vida e planejamento ambiental 
2.a. saneamento básico e água potável;

2.b. resíduos urbanos e industriais;

2.c. resíduos perigosos;

2.d. substâncias e produtos perigosos;

2.e. proteção da atmosfera/qualidade do ar;

2.f. planejamento do uso do solo;

2.g. transporte urbano;

2.h. fontes renováveis e/ou alternativas de energia.

3 . Instrumentos de política ambiental

3.a. legislação ambiental;

3.b. instrumentos econômicos;

3.c. educação, informação e comunicação ambiental;

3.d. instrumentos de controle ambiental;

3.e. avaliação de impacto ambiental;

3.f. contabilidade ambiental;

3.g. gerenciamento ambiental de empresas;

3.h. tecnologias ambientais (pesquisa, processos e produtos);

3.i. sistemas de informação;

3.j. emergências ambientais;

3.k. valoração de produtos e serviços ambientais.

4. Atividades produtivas ambientalmente sustentáveis

4.a. ecoturismo;

4.b. agropecuária sustentável;

4.c gestão ambiental empresarial;

4.d. manejo florestal sustentável;

4.e. pesca sustentável. (Mercosul, 2001)

Os recursos hídricos estão destacados no subitem $\mathrm{f}$ da área 1 , "Gestão sustentável dos recursos naturais". Porém, eles também podem estar relacionados a outras áreas, como a 2 sobre "Qualidade de vida e planejamento ambiental", que em seu subitem a estabelece o saneamento básico e a água potável como focos de atenção, e a 3, "Instrumentos de política ambiental", em especial nos subitens de a até o d, que tratam, respectivamente, de legislação ambiental, dos instrumentos econômicos, da educação ambiental e dos instrumentos de controle ambiental.

Como nos demais instrumentos do Mercosul, a resolução de controvérsias do Acordo sobre Meio Ambiente está sujeita aos termos do Protocolo de Olivos.

\section{Gestão compartilhada do Aqüífero Guarani}

Apesar do reconhecimento entre as partes do Mercosul nas quais ocorre o Sistema Aqüífero Guarani de sua situação privilegiada em termos de abastecimento hídrico no médio e longo prazos, não houve um avanço expressivo na regulamentação ambiental, em especial no que se refere ao uso compartilhado 
de recursos hídricos. A ausência de regulamentação regional para a gestão compartilhada dos recursos hídricos subterrâneos não deve ser considerada uma dificuldade. Ela pode ser superada por meio do diálogo entre as partes.

$\mathrm{O}$ Mercosul funciona melhor como instrumento de estímulo a trocas comerciais entre seus membros, objetivo inicial de sua criação, do que como meio para regulamentar a ação ambiental entre seus integrantes. No caso dos recursos hídricos subterrâneos, é fundamental que seja promovida uma maior articulação de informações e conhecimentos sobre a dinâmica natural do Sistema Aqüífero Guarani para que as decisões possam ser tomadas de maneira mais consciente. A cooperação entre as partes atende aos objetivos de criação do Mercosul e deve ser cada vez maior e envolver instituições de pesquisa e órgãos nacionais gestores de recursos hídricos.

A estrutura de decisões do bloco de países condiz com sua meta inicial, articular interesses para facilitar trocas comerciais. Ela também oferece dispositivos de regulação ambiental que devem ser ao menos experimentados na gestão dos recursos hídricos, em especial os subterrâneos. Com isso pode-se ganhar um tempo precioso na necessária regulamentação do uso dos recursos hídricos subterrâneos do Sistema Aqüífero Guarani.

Buscar construir novas formas institucionais específicas para a gestão do Aqüífero Guarani pode se mostrar pouco eficaz e demorado, ainda mais por se tratar de países sem tradição de gestão compartilhada de recursos naturais. Ressaltar e valorizar os meios já existentes, resultado de inúmeras reuniões e de um grande esforço multilateral, não implica reconhecer que eles são suficientes para levar a bom termo o uso de recursos hídricos subterrâneos. Mas eles devem ser o ponto de partida para avançar para o entendimento e congraçamento entre os países que detêm os estoques subterrâneos estratégicos que o Sistema Aqüífero Guarani representa.

O tempo não pára, o uso dos recursos hídricos também... por isso, é preciso ser ágil para evitar uma degradação dos estoques de água doce subterrânea como se verificou em outras partes do planeta por falta de diálogo entre países.

Notas

l Para aprofundar esse aspecto, ver Ribeiro (2008).

2 Cf. <http://www.daee.sp.gov.br>, acessado em dezembro de 2005.

3 Outro uso dos recursos do aqǘfero, que não será destacado neste trabalho, é a exploração da energia geotérmica. Ela foi estimada em cerca de $280 \mathrm{mw}$ ano $/ \mathrm{km}^{2}$ e pode ser utilizada para secagem de grãos e aquecimento de água, entre outros fins.

4 Em 2005, a Venezuela solicitou seu ingresso formal ao bloco, o que até o momento não ocorreu, o que ampliaria a área para cerca de $12.912 .000 \mathrm{~km}^{2}$ e cerca de $236 \mathrm{mi}-$ lhões de habitantes. Na condição de observadores, Bolívia e Chile também freqüentam as reuniões das partes. Mas até o momento não expressaram claramente desejo de ingressar no bloco de países. 
Referências bibliográficas

ARAÚJO, L. M. et al. Acuifero Gigante del Mercosur en Argentina, Brasil, Paraguay y Uruguay: mapas hidrogeológicos de las formaciones Botucatu, Piramboia, Rosario del Sur, Buena Vista, Misiones y Tacuarembó. UFPR y Petrobras, 16p. Curitiba, Paraná Brasil, 1995.

BORGHETTI, N. et al. Aqüífero Guarani: a verdadeira integração dos países do Mercosul. Curitiba: Imprensa Oficial, 2004.

MERCOSUL. Tratado de Assunção, 1991.

Protocolo de Ouro Preto, 1994.

Acordo sobre Meio Ambiente, 2001.

. Protocolo de Olivos, 2002.

OEA (Organização dos Estados Americanos). Projeto Proteção Ambiental e Gerenciamento Sustentável Integrado do Sistema Aqüifero Guarani. Elaborado por André Virmond Lima Bittencourt et al. Sob a coordenação de Ernani Francisco de Rosa Filho. Fundação da Universidade Federal do Paraná para o Desenvolvimento da Ciência, da Tecnologia e da Cultura (Funpar). Curitiba: Global Environmental Facilitu; Banco Mundial, fev. 2001.

REBOUÇAS, A. C. Recursos hídricos subterrâneos da bacia do Paraná: análise de pré-viabilidade. São Paulo, 1976, 143p. Tese (Livre-Docência) - Universidade de São Paulo.

RIBEIRO, W. C. A ordem ambiental internacional. São Paulo: Contexto, 2001.

Geografia política da água. São Paulo: Annablume, 2008.

ROCHA, G. A. O grande manancial do Cone Sul. Estudos Avançados, v.11, n.30, p.191212, 1997. Disponível em: <http://www.scielo.br/scielo.php?script-sci_arttext\&pidS0103-40141997000200013\&lng-pt\&nrm-iso>.

Fontes eletrônicas

<http://www.sg-guarani.org>, acessado em dezembro de 2005.

<http://www.daee.sp.gov.br>, acessado em dezembro de 2005.

<http://www.mre.gov.br>, acessado em março de 2006.

RESUMO - Este trabalho analisa a situação institucional do Mercosul em relação à gestão compartilhada dos recursos hídricos a partir do Sistema Aqüífero Guarani, importante reservatório de águas subterrâneas que ocorre no território da Argentina, do Brasil, Paraguai e Uruguai. Inicialmente é apresentado o quadro físico do aqüífero. Em seguida, são expostos os instrumentos de gestão ambiental do Mercosul e a pertinência em deslocar para esse bloco de países a coordenação do uso do Sistema Aqüífero Guarani - SAG. Ele teve como base uma pesquisa documental e a literatura sobre o tema.

PALAVRAS-CHAVE: Aqüífero Guarani, Mercosul, Relações internacionais e meio ambiente, Gestão compartilhada dos recursos hídricos. 
ABSTRACT - This study examines the institutional situation of Mercosur in relation to the management of shared water resources from the Guarani Aquifer System, an important reservoir of groundwater that occurs in the territory of Argentina, Brazil, Paraguay and Uruguay. Initially is displayed the physical conditions of the aquifer. Then they are exposed to environmental management tools and relevance in the Mercosur move to this block of countries to coordinate the use of the Guarani Aquifer System - SAG. It was based on a documentary research and literature on the subject.

KErWORDS: Guarani Aquifer, Mercosur, International relationship and environment, Management of shared water resources.

Wagner Costa Ribeiro é geógrafo, professor dos Programa de Pós-Graduação em Ciência Ambiental (Procam) e do Programa de Pós-Graduação em Geografia Humana do Departamento de Geografia da Universidade de São Paulo. Presidente do Procam e coordenador do Grupo de Trabalho de Ciências Ambientais do Instituto de Estudos Avançados da USP. @ - wribeiro@usp.br

Recebido em 23.2.2007 e aceito em 23.3.2007. 